\title{
Preliminary investigations on extrusion of high viscosity slurry using direct writing technique
}

\author{
Ali Tesfaye Kebede ${ }^{1, *}$, Esakki Balasubramanian ${ }^{1}$, AS Praveen ${ }^{1}$, Lade Rohit ${ }^{2}$, and Kumar Arvind ${ }^{2}$ \\ ${ }^{1}$ Department of Mechanical Engineering, Vel Tech Rangarajan Dr. Sagunthala R\&D Institute of Science and Technology, \\ Avadi, Chennai, India \\ ${ }^{2}$ High Energy Materials Research Laboratory (HEMRL), Pune, Maharashtra, India
}

Received: 12 February 2020 / Accepted: 2 July 2020

\begin{abstract}
Traditionally solid propellants are manufactured using casting and molding techniques. The effective burning rate of solid propellants is strongly depended on its cross section and geometry. The preparation of mold and mandrel for the manufacturability of various geometric profiles are tedious, time consuming, increases the cost and more human efforts are needed. In order to mitigate these issues, a disruptive technology called additive manufacturing (AM) is in the verge of development. Although the method is effective, additional study must be conducted to improve the flow characteristics of slurries for the high solid loading and there is a huge necessity to reduce the prolonged curing time. The present study focuses on preliminary investigations of extrusion of high viscosity slurry using a pneumatically driven extrusion system. The slurry was prepared with a $80 \mathrm{wt} . \%$ solid loading of $\mathrm{NaCl}$ having particle sizes of $45 \mu \mathrm{m}$ and $150 \mu \mathrm{m}, 15.6 \mathrm{wt} . \% \mathrm{HTPB}$, 2.2 wt.\% TDI, 2.2 wt.\% DOA and 0.03 wt.\% of ferric acrylacetonate. The slurry was extruded with an aid of pneumatically controlled extruder and each layer was formed. Formed by extruding the slurry using $1.65 \mathrm{~mm}$ internal diameter nozzle. Infrared (IR) heater was utilized to transfer the radiational energy for partial curing of each layer and thereby adhesion of other layer was guaranteed. Simulation is performed to determine the temperature distribution using ANSYS platform for comparing the curing temperature of the printed part top surface. Preliminary experiments confirm that extrusion of slurry and heating of each layer can be effectively achieved with the proposed $3 \mathrm{D}$ printing technique. Three tensile specimens were produced in accordance with ASTMD 412-C and their corresponding mechanical properties are evaluated. The printed parts have the tensile strength of $0.7 \mathrm{MPa}$, elongation of $4.85 \%$ and modulus of elasticity of $18.5 \mathrm{MPa}$ which are comparable with the properties of conventional casted part.
\end{abstract}

Keywords: Solid loading / additive manufacturing / slurry / curing / tensile strength / FE simulation / surface temperature measurement

\section{Introduction}

Solid propellants [1] are made out of various chemical ingredients such as oxidizing agent, fuel, binder, plasticizer, hardener, stabilizer, and cross-linking agent. Different chemical ingredient proportion leads to altered physical and chemical properties. The chemical ingredient proportion is specified based on the intended applications. Traditionally solid propellants are manufactured [2] using casting and molding techniques. The preparation of mold and mandrel for various geometric profiles to achieve effective burning rate are tedious, increases the cost and more human efforts are needed. In order to alleviate

\footnotetext{
* e-mail: tesfaye4r@gmail.com
}

these issues a disruptive technology namely additive manufacturing (AM) is in the verge of development. AM technologies [3] have changed the prospective of material processing in different fields. This technology is equipped with an ability to create complex 3D parts without the use of tooling, which can reduce up to $50 \%$ of the product lead time. Due to the strange feature of AM techniques such as time efficient, cost-effective and can print wide range of materials such as ceramics [4-6], metals [7-9], food [10-12] and thermoplastics [13-15]; the AM process attracted a great deal of attention in the areas of automotive [16], aeronautical [17], medical [18], robotics [19], electronics [20], construction [21] and consumer goods manufacturing [22]. Recently, the additive manufacturing of solid propellant has gained interest due to the ability to form complex and intricate shapes. Solid propellants can 
generate high heat output and energy density upon ignition. However, in order to attain an effective solid propellant, suitable material composition and geometry are the crucial parameters which influences the propulsion performance characteristics. The printing process can control the burning rate of reactive materials. The geometric flexibility provided by the AM process allows precise control of the solid propellant burning rate.

Due to the above mentioned advantages, recently researcher around the globe used different AM techniques to manufacture solid propellants. Murray et al. (2017) [23] successfully used the combinatorial inkjet printing for the deposition of nanoaluminum (nAl) and nanocopper (II) oxide $(\mathrm{nCuO})$ energetic materials. In this technique, the materials can be mixed and stored as inert components, which improves safety and self-stability. However, they used low solid loading ( $>6$ vol.\%) which may affect the reactivity of energetic material. McClain et al. (2018) [24] printed propellant composition slurry with $85 \%$ of AP as solid loading and UV-curable polyurethane along with hydroxyl-terminated polybutadiene (HTPB) as a binder. The slurry was extruded through the nozzle tip with the help of ultrasonic vibration at $30.3 \mathrm{KHz}$ frequency and $8 \mu \mathrm{m}$ amplitude. Study conducted by Chandru et al. (2018) [25] on AM of solid rocket propellant grains shows that the feasibility of using extrusion based 3D printing for the development of different part geometries. They successfully printed slurry composed of AP, HTPB and iron oxide. However, they have not mentioned about the solid loading and viscosity of the prepared ink as well as the combustion performance between printed and traditionally manufactured grains. Fleck et al. (2017) [26] developed printable reactive filament slurry consisting of $20 \%$ mass loading of aluminums $(\mathrm{Al})$ and polyvinylidene fluoride (PVDF) used as a binder. The slurry was printed using a commercial filament extruder. The performance of the printing process of was evaluated through comparing the quality of printed energetic samples with the standard $3 \mathrm{D}$ printed materials. All the research focused on AM of energetic materials and solid propellants with low solid loading which may affect the reactivity and burning rate of the materials.

The application of AM process has not been leveraged by Indian research groups for manufacturing various prototypes and functional components. However, $3 \mathrm{D}$ Printing (3DP) of solid propellants is novel research and especially minimizing the curing time of solid propellants using low cost IR/UV heaters are not addressed in the literature. This work is oriented towards fulfilling the above-mentioned need and hence it is justifiable.

Development of a 3DP process has following characteristics can be of definitive use to High energy materials groups of Defense Research \& Development Organization (DRDO):

- Compatibility with wide range of chemical compositions.

- Ability to produce parts layer-by-layer without support structures

- Non usage of high power lasers and utilizing low cost heating systems for curing.
By referring to the published body of literature on the topic of manufacturing solid propellant, it has been affirmed that proposed 3DP process offers excellent scope to align with above functionalities. In India, IISc has started using direct extrusion technique to deposit layerby-layer of prepared slurry. After completion of all the layers, the $3 \mathrm{D}$ printed structure is kept in the oven for 6-7 days at $60{ }^{\circ} \mathrm{C}$. In order to reduce the curing time, proposed work focuses on incorporation of IR/UV heating systems in the 3DP process after deposition of each layer. Hence a significant need exists for conducting of the proposed research studies. Commercial AM processes like stereo lithography [27], Selective laser sintering [28] and electron beam melting [29] produces the parts by infusion of laser energy which are very costly. But in the case of proposed $3 \mathrm{DP}$ process, fusions of slurry through low cost heaters tremendously reduce the cost of machine and subsequently manufacturing cost is reduced. The proposed 3DP process can pose several challenges to the researchers with reference to layer curing, precise delivery of high viscous slurry, geometric and dimensional fidelity and also examining mechanical strength characteristics.

As this process has potential ability to produce solid propellants without the use of lasers or part specific tools, jigs and fixtures, it is inferred that proposed $3 \mathrm{DP}$ technology would be highly relevant to manufacture solid propellants in a cost effective manner. Also the openness of $3 \mathrm{DP}$ process would enable the proposers to investigate wide array of chemical composition beyond the initial set of compositions thereby opening new vistas in manufacturing of solid propellants. In addition, various geometric profiles or patterns of solid propellants can be visualized swiftly as per the requirement of High Energy Materials Research Laboratory (HEMRL).

\section{Materials and methods}

\subsection{Synthesis of slurry}

The main intention of this work is to prepare high solid slurry that can be extruded through small-diameter nozzle and to examine the feasibility of uniform heating of each layer of the cured part that cure layer by layer fashion using full trough element (FTE) ceramic infrared heater. Owning to high cost and flammable nature of the solid propellant, an extraordinary safety measures during curing is necessary. Therefore, ordinary home salt viz. $\mathrm{NaCl}$ was used as solid loading powder during the preparation of printer slurry, which tremendously minimize the raw materials and process cost of experimental investigation of this work. The slurry has been prepared by gently mixing $15.6 \%$ of Hydroxyl-terminated polybutadiene (HTPB) as fuel/ binder, $2.2 \%$ Toluene Diisocyanate (TDI) as curing agent and $0.03 \%$ of Ferric acetylacetonate as a catalyst for 15 min. Then, $80 \%$ of $\mathrm{NaCl}$ has been added in the mixture and the mixing process continue to another $15 \mathrm{~min}$. In general, the burning rate of printed grain solid propellant is improved by increasing the amount of solid loading on the propellant composition slurry. Therefore, preliminary extrusion experimental studies were conducted at different percentage of solid loading (70-85\%) 


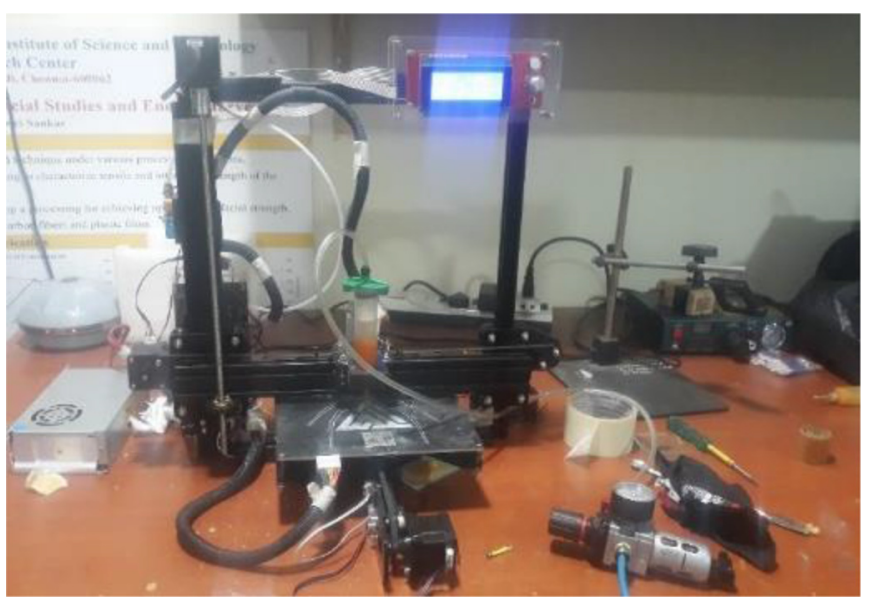

Fig. 1. 3D printer system.

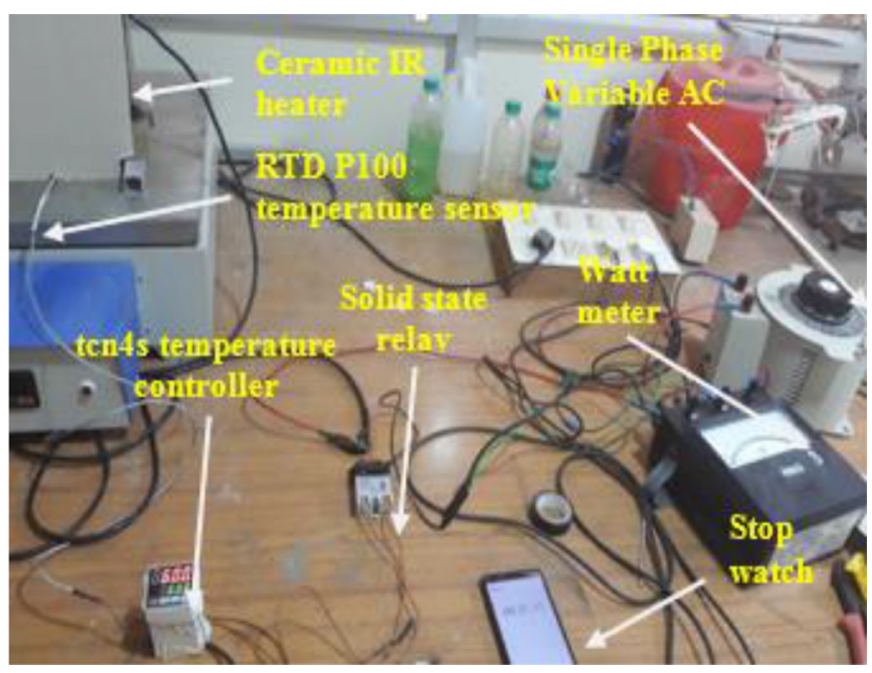

Fig. 2. IR heating system.

to obtain the printable slurry composition. However, as per our experimental analysis, if the solid loading is greater than $80 \%$, the slurry composition has obtained more viscosity and unable to extrude the slurry during the printing process. The clogging also occurs at the nozzle of $1.65 \mathrm{~mm}$ diameter. Hence, through iterative studies, the following composition: $80 \% \mathrm{NaCl}, 15.6 \% \mathrm{HTPB}, 2.2 \% \mathrm{TDI}$, $2.2 \%$ DOA and $0.03 \%$ Ferric acetylacetonate was arrived that has obtained good dispersion of slurry at maximum solid loading. The slurry composition was tuned by considering the extrusion ability from the 3DP nozzle and to keep shape precision during deposition of one layer over the previously printed layer.

\subsection{Set-up for printing and heat treatment process}

Two separate experimental setups such as slurry printing and heating systems were arranged as depicted in Figures 1 and 2 respectively. The printing system was developed by modifying a desktop type fused deposition modeling (FDM) printer and the extrusion of the slurry was driven

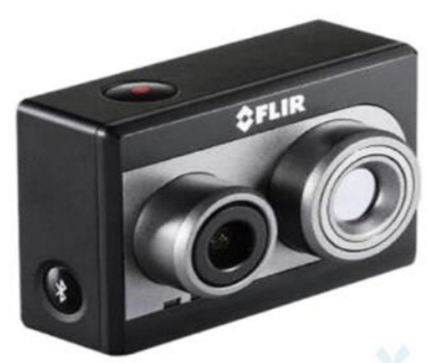

Fig. 3. FLIR Duo Pro R thermal camera.

by compressed air supply by means syringe through a $1.65 \mathrm{~mm}$ internal diameter nozzle.

The heating system was built from ceramic infrared heater and closed loop temperature controlling system was implemented that consists of Tcn 4 s temperature controller (i.e. PID controller), RTD P100 temperature sensor and solid state relay. In addition, single phase variable $\mathrm{AC}$ supply in conjunction with watt matter was equipped with heating system to control the heater input power precisely and stop watch has been used to measure the curing time. The printing process was carried out through printing single layer on the substrate and heating the printed slurry at $60{ }^{\circ} \mathrm{C}$ for $15 \mathrm{~min}$ and subsequently the second layer was printed over the first cured layer. The printing and heating process continues until the entire layers have been printed and cured.

\subsection{Temperature distribution measurement}

The capability of the heater to produce uniform temperature distribution over the printed part was measured with FLIR Duo Pro R thermal camera, which is shown in Figure 3. In the present work, firstly the thermal images were taken using FLIR Duo Pro R thermal camera immediately after heating each layer of printed part using ceramic infrared heater. The obtained thermal images were further analyzed with FLIR-tool software. In order to measure the temperature distribution over the top printed surface, three lines were drawn. Along each line, the maximum, minimum and average temperature were determined. Moreover, thermal module of ANSYS 19.2 version software was used to develop a numerical model based on the control volume method and to simulate the temperature distribution of the part.

The irradiance, which is the absorbed heat flux by the cured surface of printed part is considered as the source of heat for the simulation in ANSYS platform. At the beginning of the numerical work, a three-dimensional part with dimensions of $3.2 \times 12.7 \times 125 \mathrm{~mm}$ was modelled using the geometric modelling tool of ANSYS. Since approximately $80 \%$ of the printed parts were made of $\mathrm{NaCl}$, the engineering material properties of the modeled parts were considered to be $\mathrm{NaCl}$ material properties alone (see Table 1). The steady-state thermal simulation was carried out by applying heat flux boundary conditions of $60 \mathrm{~kW} / \mathrm{m}^{2}$ at the top of the part surface, and the rest of the surface was exposed to an ambient temperature of $26^{\circ} \mathrm{C}$. 


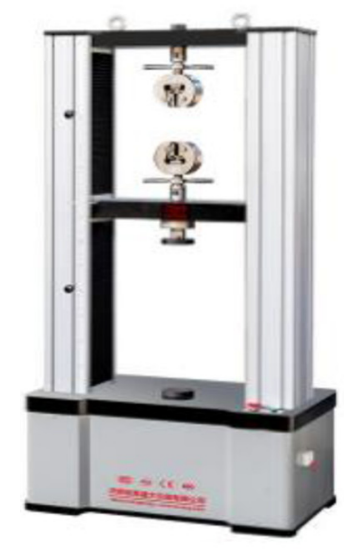

(a)

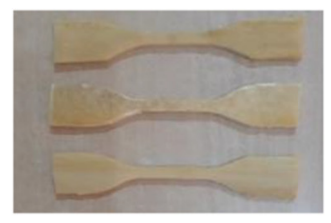

(b)
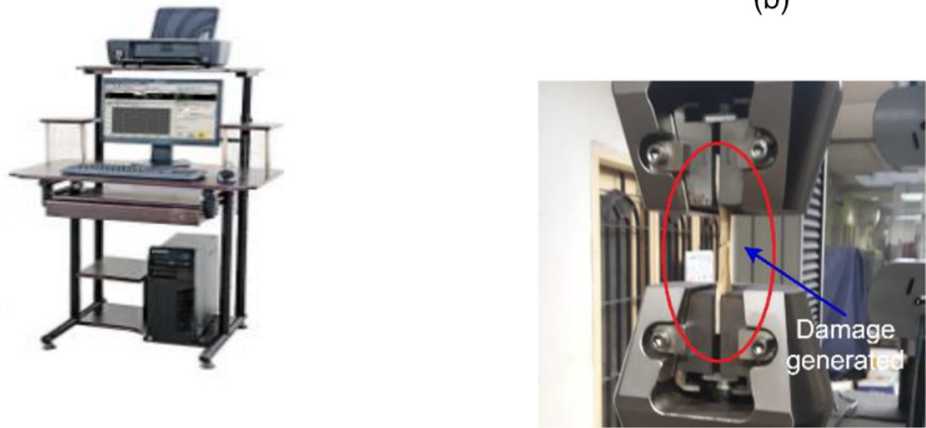

(c)

Fig. 4. Tensile strength testing. (a) WDW-100 computer control electronic universal testing machine; (b) tensile strength specimen (ASTMD 412-C); (c) Fracture generation during the test.

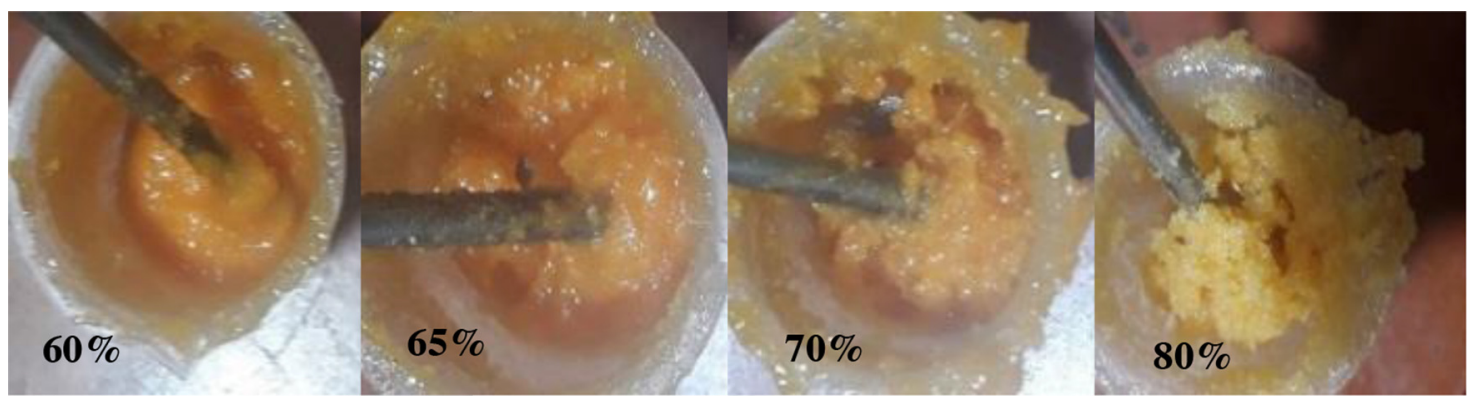

Fig. 5. Slurry composition with different solid loading $(\mathrm{NaCl})$ percentage.

Table 1. Material properties of $\mathrm{NaCl}$.

\begin{tabular}{ll}
\hline Properties & Values \\
\hline Coefficient of thermal expansion $\left({ }^{\circ} \mathrm{C}^{-1}\right)$ & $4.45 \times 10^{-5}$ \\
Thermal conductivity $\left[\mathrm{W} / \mathrm{m}{ }^{\circ} \mathrm{C}\right]$ & 6.15 \\
Specific heat $\left[\mathrm{J} / \mathrm{kg}{ }^{\circ} \mathrm{C}\right]$ & 871 \\
Young's modulus $[\mathrm{Pa}]$ & $3.27 \times 10^{10}$ \\
Poisson's ratio & 0.203 \\
Bulk modulus $[\mathrm{Pa}]$ & $1.83 \times 10^{10}$ \\
Shear modulus $[\mathrm{Pa}]$ & $1.3591 \times 10^{10}$ \\
\hline
\end{tabular}

\subsection{Tensile strength measurement}

Three ASTM D412-C standard tensile strength test sample, shown in Figure 4b, were additively fabricated from $80 \%$ solid loaded slurry composition using direct extrusion based printer. During the fabrication of each specimens, the slurry was printed with a linear infill pattern at $1 \mathrm{~mm} / \mathrm{s}$ printer feed rate, the printing direction is kept along the length of the specimen and the extrusion of the slurry is achieved through $1.65 \mathrm{~mm}$ diameter nozzle which was driven with $7 \mathrm{MPa}$ compressed air supply. The curing of each layer of the test sample was carried out heating the each layer by using the FTE serious ceramic infrared heater for $15 \mathrm{~min}$ at a temperature of $60^{\circ} \mathrm{C}$. Tensile test was performed on the WDW-100 universal computer control electronic testing machine shown in Figure 4a. The fractured tensile specimen during the course of experiments is shown in Figure 4c.

\section{Results and discussion}

The main intention of the present work is to check the feasibility of using 3DP techniques to fabricate propellant grain directly from CAD models without much regard to its geometric complexity. The printing of composite grain was done by curing of layer by layer instead of doing bulk curing of the entire printed composite slurry layers at ones, which radically reduce the time required for curing. In order to increase the burning rate of solid propellant, the slurry composition must be prepared with a maximum solid loading. Therefore, extrusion experiments were done at different solid loading percentage to get printable slurry composition as depicted in Figure 5. Due to the scarcity and the need of special handling precaution of propellant, 


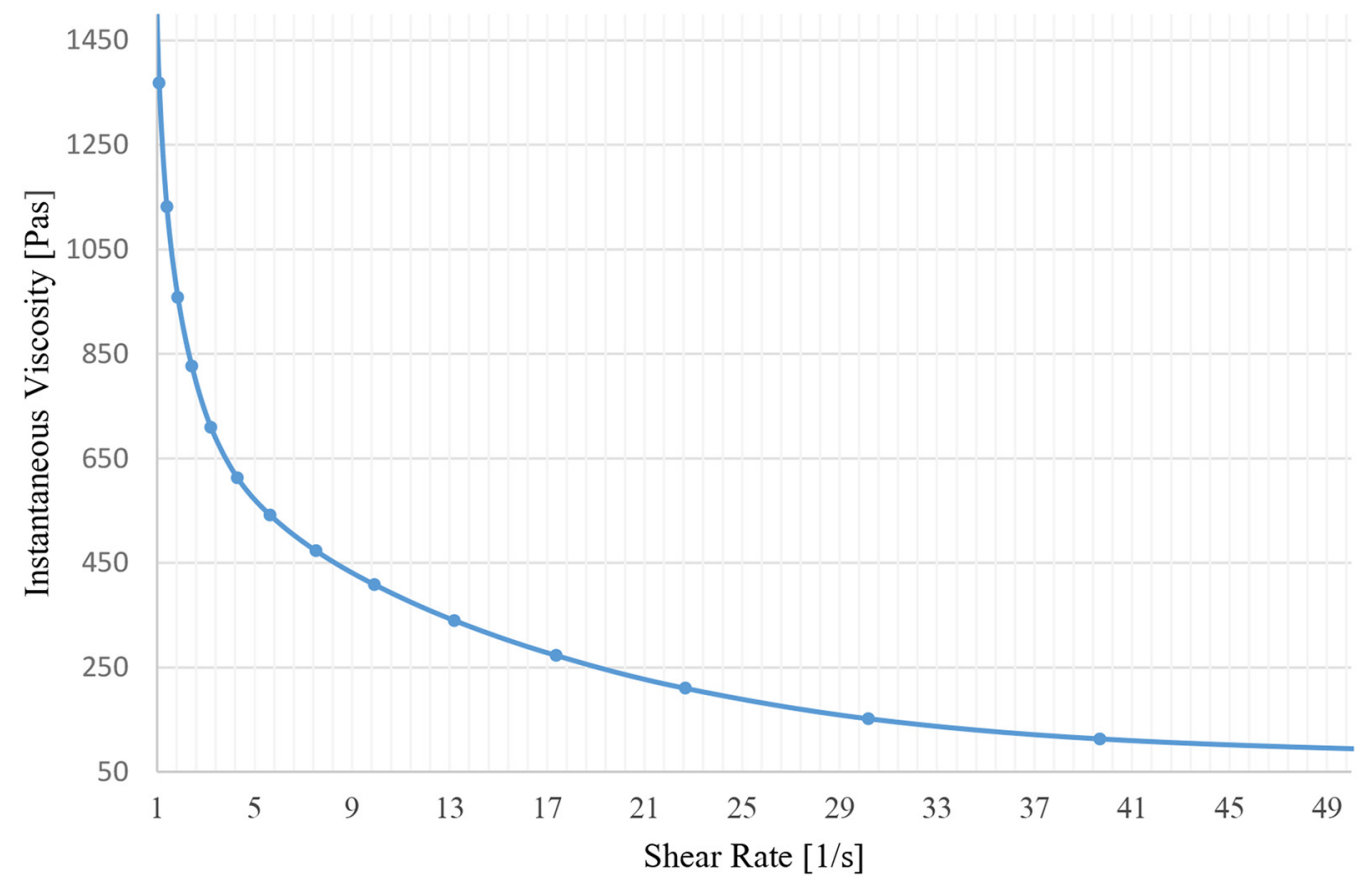

Fig. 6. Shear rate vs instantaneous viscosity curve.

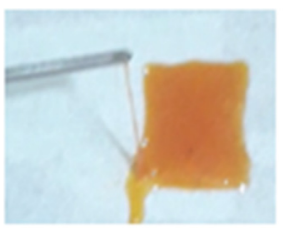

$5 \mathrm{~min}$

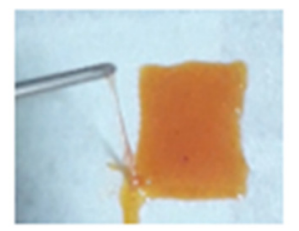

$10 \mathrm{~min}$

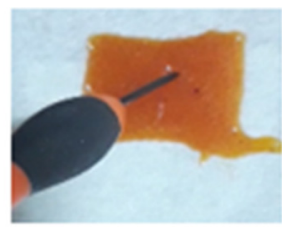

$15 \mathrm{~min}$
Fig. 7. The effect of time on curing.

$\mathrm{NaCl}$ was used in place propellant composite during this study and the final experimentally determined composite slurry ratio that was capable to extrude from the extrusion system is $80 \% \mathrm{NaCl}, 15.6 \% \mathrm{HTPB}, 2.2 \%$ TDI, $2.2 \% \mathrm{DOA}$ and $0.03 \%$ Ferric acetylacetonate. The instantaneous viscosity of the final slurry composition was determined using Bohlin Gemini II Rheometer and with respect to shear rate is depicted in Figure 6. It is observed that the slurry compositions exhibited shear thinning behavior, which means the viscosity of the slurry decrease with the increase of shear rate.

The state of curing has been checked by pulling out the cured sample using a needle after heating a certain amount of time at $60^{\circ} \mathrm{C}$ which is controlled by PID controller. The curing time required to cure single layer is depicted in Figure 7. As observed from the figure, the viscosity of the slurry increase as the heating time increases and the slurry has been successfully changed into composite grain at $15 \mathrm{~min}$ of heating. However, no feasible change has been observed on the properties of cured grain with further heating. As shown in Figure 8, the multilayer composite grain fabrication was possible by heating the slurry at $60^{\circ} \mathrm{C}$ constant temperature for 15 min duration and strong bond between the grain layers was achieved.

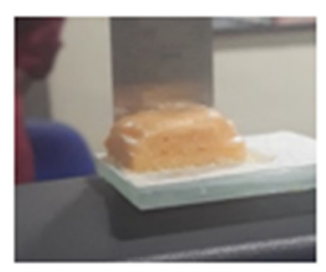

4 layers

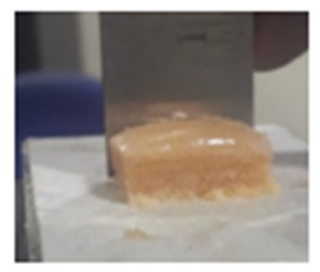

6 layers
Fig. 8. Printed multi-layer.

The temperature distribution over the surface of cured parts was measured at different heating time using the high-resolution thermal camera and the thermal images were analyzed with FLIR-tool software as shown in Figure 9. In order to measure the temperature distribution over the top printed surface, three lines were drawn. Along each line, the maximum, minimum and average temperature were determined. It is found that the measured average temperature difference between the three lines that are found at a different location of the surface of the part was insignificant. A small temperature variation between the lines asserted that the printed slurry layer was cured by ceramic infrared heater to achieve uniform temperature. This might be happened due to the heat transfer rate through radiation is fast which made the FTE serious ceramic infrared heater was capable to deliver its heat energy with minimum temperature variation (i.e. $59.7 \approx$ $60^{\circ} \mathrm{C}$ ). In addition, the variation of temperature over the printed slurry layer after 8 and 15 min was observed as almost negligible.

The thermal analysis results are compared with cured layer. The temperature distribution of the $\mathrm{FE}$ simulation results is shown in Figure 10. Based on the energy 


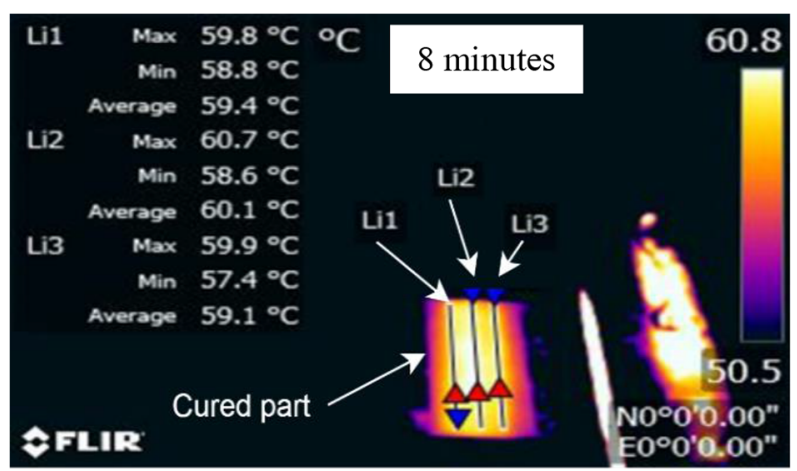

Thermal image

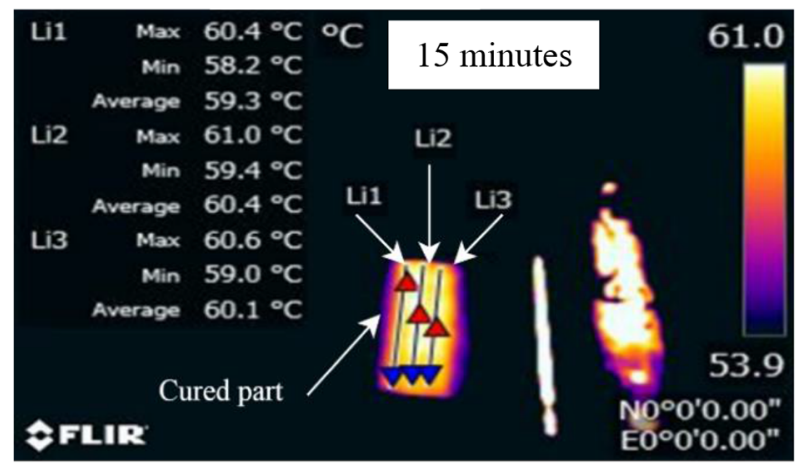

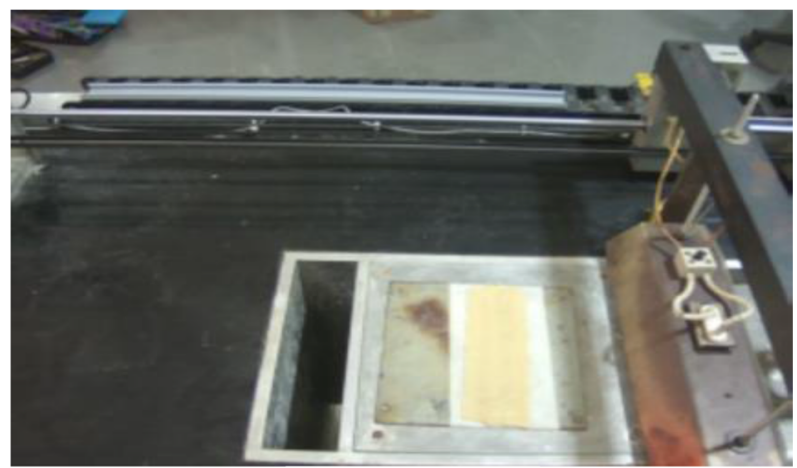

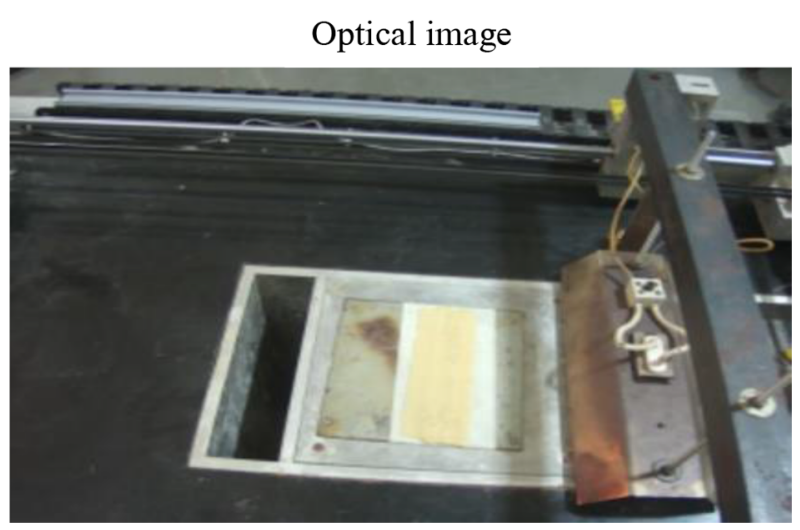

Fig. 9. Temperature distribution contour measured by thermal camera.
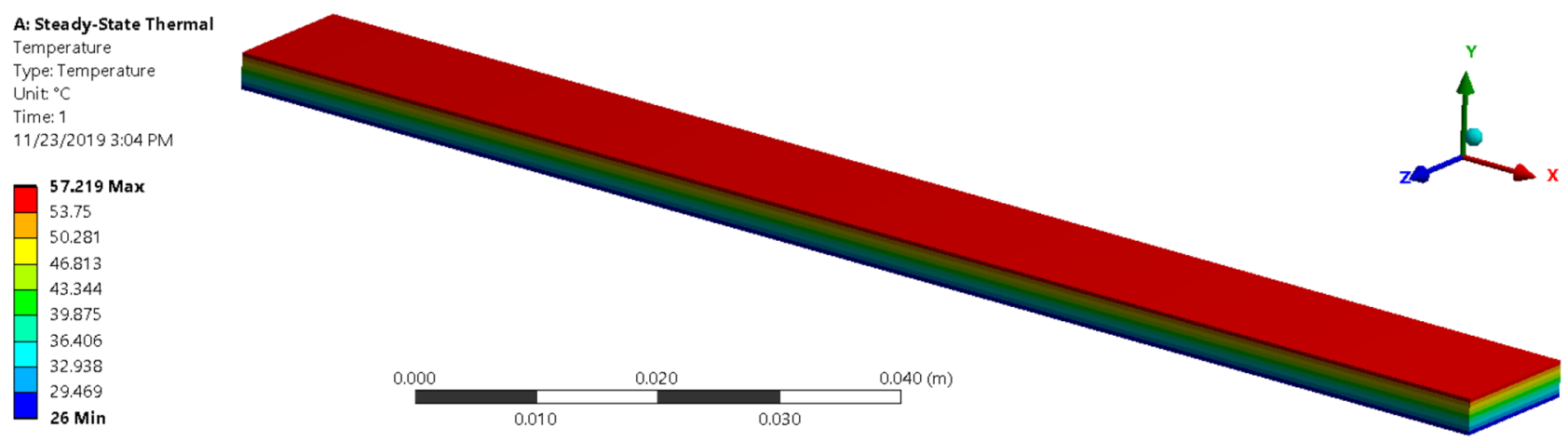

Fig. 10. Temperature distribution contour simulated by ANSYS.

absorption of the simulation result of the cured part, the temperature distribution over the cured surface becomes uniform and the upper surface has obtained uniform temperature of $57.22^{\circ} \mathrm{C}$ and gradually decreases from the top to bottom surface. Swift heat transfer by infrared radiation and low thermal conductivity of parts played a significant role in achieving uniform temperature on the upper surface. The FE model validation is crucial to validate the simulation results. Minimum measurement error (i.e. $4.2 \%$ ) was observed between the numerical and average experimental values.

In addition, the tensile strength characteristics of the printed part were examined and the results are given in Table 2. The average of those three specimens results were considered and the corresponding stress-strain curve is depicted in Figure 11. The layer-by-layer curing process using FTE serious infrared heater was able to produce part with maximum tensile strength of $0.63 \mathrm{MPa}$ and elastic modules of $16.45 \mathrm{MPa}$. These strength values show significant improvement over the tensile strength characteristics of previously manufactured solid propellant [25] through conventional cast (i.e. tensile strength of $0.34 \mathrm{MPa}$ ) and $3 \mathrm{D}$ printed (i.e. tensile strength of $0.32 \mathrm{MPa}$ ) process.

\section{Conclusion}

The fabrication of composite grain was demonstrated directly from CAD file using additive manufacturing method without the help of mandrels or other tooling. The printer extrusion system, which is driven by 
Table 2. Mechanical properties of 3D printed tensile test specimens.

\begin{tabular}{llll}
\hline Test specimens & Tensile strength $(\mathrm{MPa})$ & Elastic modulus $(\mathrm{MPa})$ & \% of elongation \\
\hline Sample 1 & 0.63 & 13.42 & 6.97 \\
Sample 2 & 0.70 & 18.50 & 4.85 \\
Sample 3 & 0.57 & 17.36 & 5.15 \\
Average & 0.63 & 16.45 & 5.66 \\
\hline
\end{tabular}

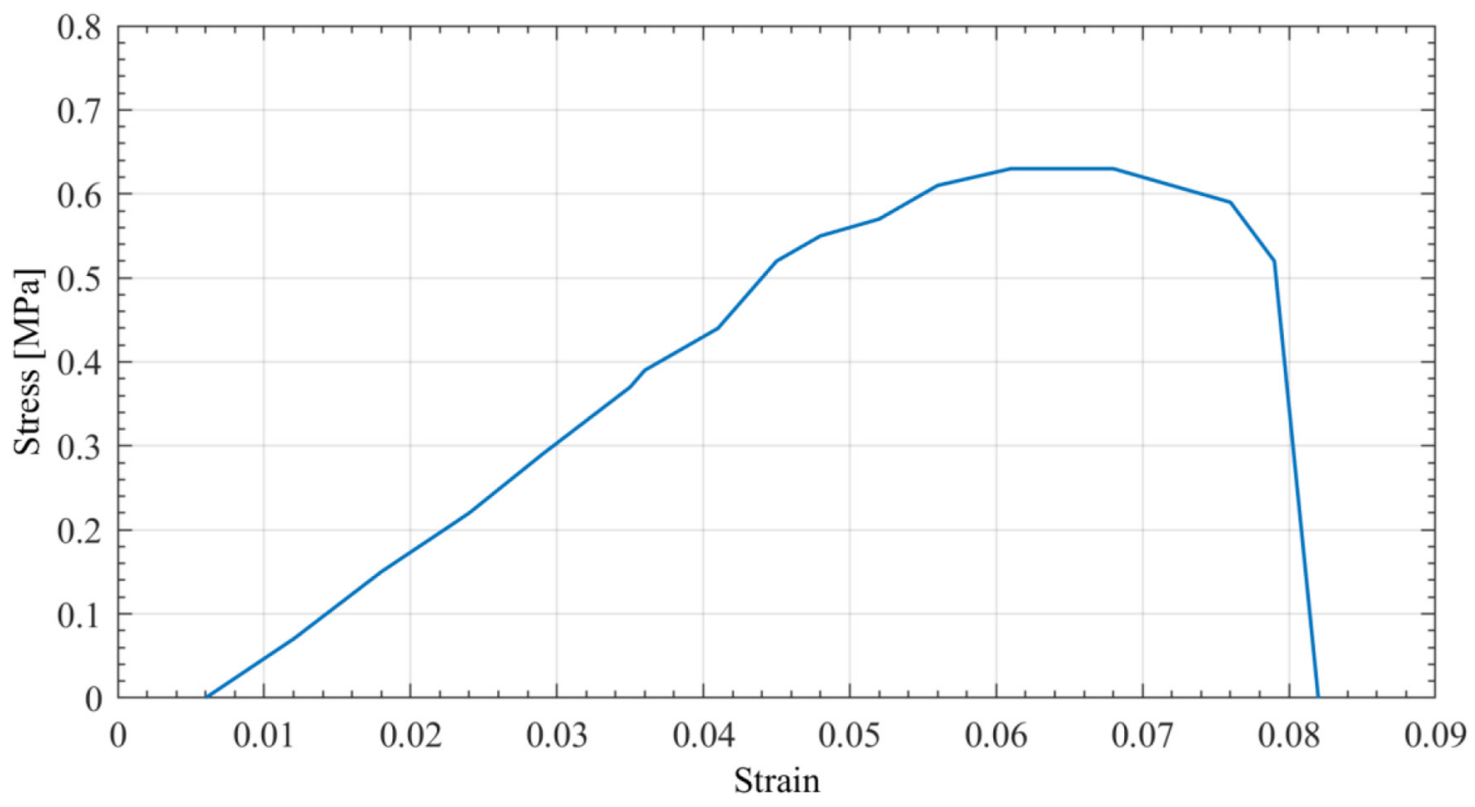

Fig. 11. Stress-strain diagram of 3DP sample under uniaxial tensile load.

compressed air supply, was viable to extrude the slurry composite trough at $1.65 \mathrm{~mm}$ internal nozzle diameter with $80 \%$ solid loading. The novel and simple approach of layer by layer heating technique (15 min for each layer) using low cost ceramic infrared heater could significantly minimized the curing time (from 7 days to 3 days of bulk curing) and cost of grain composite production.

The temperature distribution over the cured surfaces, heated at $60^{\circ} \mathrm{C}$ using a ceramic infrared-based fast heating system, was investigated by experimental measurement and surface temperature was compared with thermal analysis of ANSYS simulation. Based on the simulation result, a uniform temperature of $57.22^{\circ} \mathrm{C}$ was observed on the upper surface of the model and was gradually reduced from the upper to the lower surface. Furthermore, the temperature distribution on the top surface of the cured part was measured with a high-resolution thermal camera, and about $4.2 \%$ deviation is observed with respect to simulation results. Therefore, the experimental and simulation results clearly shows that the FTE serious ceramic infrared heater is feasible to heat the printed slurry with almost the targeted (i.e. $60^{\circ} \mathrm{C}$ ) temperature during the curing process.

In addition, tensile specimens were successfully manufactured and tensile strength was measured. A maximum tensile strength of $0.63 \mathrm{MPa}$ and elastic modulus of $16.45 \mathrm{MPa}$ were achieved with current printing process and layer-by-layer curing scheme. Therefore, the present heating approach introduced in this work can be extended to fabricate composite solid propellant grain using additive manufacturing techniques. In future, instead of pneumatic driven extrusion system, the use of screw driven extrusion system can solve the issue of extrusion of propellant composition slurry with very high solid loading.

\section{References}

1. R. Carro, M. Stephens, J. Arvanetes, A. Powell, E. Petersen, C. Smith, High-pressure testing of composite solid propellant mixtures: burner facility characterization, in 41st AIAA ASME/SAE/ASEE Jt. Propuls. Conf. Exhib., no. July, pp. 1-9, 2005, doi: 10.2514/6.2005-3617

2. G.P. Sutton, Rocket Propulsion Elements (2001)

3. T.D. Ngo, A. Kashani, G. Imbalzano, K.T.Q. Nguyen, D. Hui, Additive manufacturing (3D printing): a review of materials, methods, applications and challenges, Compos Part B 143, 172-196 (2018)

4. L. Yang, H. Miyanaji, Ceramic additive manufacturing: a review of current, Solid Free. Fabr. 2017, 652-679 (2017) 
5. R. Galante, C.G. Figueiredo-Pina, A.P. Serro, Additive manufacturing of ceramics for dental applications: a review, Dent. Mater. 35, 825-846 (2019)

6. S. Huang, C. Ye, H. Zhao, Z. Fan, Additive manufacturing of thin alumina ceramic cores using binder-jetting, Addit. Manuf. 29, 100802 (2019)

7. Z. Prevorovsky, J. Krofta, J. Kober, NDT in additive manufacturing of metals, in NDT Prog. 2017 - 9th Int. Work. NDT Progress, Proc., vol. 2017-Octob, pp. 75-84, 2017, doi: 10.1016/j.actamat.2016.07.019

8. F. Khodabakhshi, M.H. Farshidianfar, S. Bakhshivash, A.P. Gerlich, A. Khajepour, Dissimilar metals deposition by directed energy based on powder-fed laser additive manufacturing, J. Manuf. Process. 43, 83-97 (2019)

9. Y. Qin et al., Additive manufacturing of biodegradable metals: current research status and future perspectives, Acta Biomater. 98, 3-22 (2019)

10. J.I. Lipton, M. Cutler, F. Nigl, D. Cohen, H. Lipson, Additive manufacturing for the food industry, Trends Food Sci. Technol. 43, 114-123 (2015)

11. N. Nachal, J.A. Moses, P. Karthik, C. Anandharamakrishnan, Applications of 3D printing in food processing, Food Eng. Rev. 11, 123-141 (2019)

12. S.L. Voon, J. An, G. Wong, Y. Zhang, C.K. Chua, 3D food printing: a categorised review of inks and their development, Virtual Phys. Prototyp. 14, 203-218 (2019)

13. F. Ning, W. Cong, J. Qiu, J. Wei, S. Wang, Additive manufacturing of carbon fiber reinforced thermoplastic composites using fused deposition modeling, Compos. Part B Eng. 80, 369-378 (2015)

14. J.M. Chacón, M.A. Caminero, P.J. Núñez, E. García-Plaza, I. García-Moreno, J.M. Reverte, Additive manufacturing of continuous fibre reinforced thermoplastic composites using fused deposition modelling: effect of process parameters on mechanical properties, Compos. Sci. Technol. 181, 107688 (2019)

15. C. Luo, X. Wang, K.B. Migler, J.E. Seppala, Upper bound of feed rates in thermoplastic material extrusion additive manufacturing, Addit. Manuf. 32, 101019 (2020)

16. A. Andrearczyk, P. Baginski, P. Klonowicz, Numerical and experimental investigations of a turbocharger with a compressor wheel made of additively manufactured plastic, Int. J. Mech. Sci. 178 (2020)

17. U. Fasel, D. Keidel, L. Baumann, G. Cavolina, M. Eichenhofer, P. Ermanni, Composite additive manufacturing of morphing aerospace structures, Manuf. Lett. 23, 85-88 (2020)

18. C.J. Culbreath, B. Gaerke, M.S. Taylor, S.D. McCullen, O.T. Mefford, Effect of infill on resulting mechanical properties of additive manufactured bioresorbable polymers for medical devices, Materialia 12 (2020) doi: 10.1016/j. mtla.2020.100732

19. E.B. Joyee, Y. Pan, Additive manufacturing of multimaterial soft robot for on-demand drug delivery applications, J. Manuf. Process. 56, 1178-1184 (2020)

20. T. Santaniello, P. Milani, Additive nano-manufacturing of 3D printed electronics using supersonic cluster beam deposition, Front. Nanosci. 15, 313-333 (2020)

21. F. Craveiro, J.P. Duarte, H. Bartolo, P.J. Bartolo, Additive manufacturing as an enabling technology for digital construction: a perspective on Construction 4.0, Autom. Constr. 103, 251-267 (2019)

22. M. Bogers, R. Hadar, A. Bilberg, Additive manufacturing for consumer-centric business models: Implications for supply chains in consumer goods manufacturing, Technol. Forecast. Soc. Change 102, 225-239 (2016)

23. A.K. Murray et al., Two-component additive manufacturing of nanothermite structures via reactive inkjet printing, J. Appl. Phys. 122, 1-6 (2017)

24. M.S. McClain, I.E. Gunduz, S.F. Son, Additive manufacturing of ammonium perchlorate composite propellant with high solids loadings, Proc. Combust. Inst. 37, 3135-3142 (2019)

25. R.A. Chandru, N. Balasubramanian, C. Oommen, B.N. Raghunandan, Additive manufacturing of solid rocket propellant grains, J. Propuls. Power 34, 1090-1093 (2018)

26. T.J. Fleck, A.K. Murray, I.E. Gunduz, S.F. Son, G.T.C. Chiu, J.F. Rhoads, Additive manufacturing of multifunctional reactive materials, Addit. Manuf. 17, 176-182 (2017)

27. J.G. Zhou, D. Herscovici, C.C. Chen, Parametric process optimization to improve the accuracy of rapid prototyped stereolithography parts, Int. J. Mach. Tools Manuf. 40, 363-379 (2000)

28. S. Kumar, Selective laser sintering: a qualitative and objective approach, JOM 55, 43-47, doi: 10.1007/s11837003-0175-y

29. X. Li, C. Wang, W. Zhang, Y. Li, Fabrication and characterization of porous Ti6Al4V parts for biomedical applications using electron beam melting process, Mater. Lett. 63, 403-405 (2009)

Cite this article as: Ali Tesfaye Kebede, Esakki Balasubramanian, AS Praveen, Lade Rohit, Kumar Arvind, Preliminary investigations on extrusion of high viscosity slurry using direct writing technique, Int. J. Simul. Multidisci. Des. Optim. 11, 15 $(2020)$ 